\title{
Functional and Dysfunctional Fear of Crime in Inner Sydney: Findings from the Quantitative Component of a Mixed-Methods Study
}

\author{
Murray Lee*, Sydney Law School \\ Jonathan Jackson, LSE \& Sydney Law School \\ Justin R. Ellis, University of Newcastle \\ * Murray Lee, Law School Building (F10), Eastern Ave, Camperdown NSW 2006, Australia. \\ murray.lee@sydney.edu.au
}

\begin{abstract}
This article presents the quantitative findings from a mixed-method study of perceptions of crime in inner Sydney. A survey was deployed via Computer Assisted Telephone Interview (CATI) on a randomly selected sample of the inner Sydney population $(n=409)$. We find that less than half of the participants worry about crime but that a sizable minority (13\%) indicated that they have some worry about a category of crime every week of the year or more. Building on a recent conceptual advance Gray et al. 2011), we differentiate between functional and dysfunctional fear of crime. We find that greater direct and indirect experience of victimization, believing one's neighbourhood to be disorderly, and believing that collective efficacy is low all predict moving up the scale from no worry, to functional fear, to increasingly frequent dysfunctional fear. The findings suggest gender and age are largely unrelated to worry about crime, controlling for perceptions of community disorder, perceptions of collective efficacy, direct victimisation experience and indirect victimisation experience. We conclude with some thoughts on the role of environmental cues in shifting people's functional response to perceived risk to dysfunctional patterning of emotions in people's daily lives.
\end{abstract}

\section{Key words}

Fear of crime; mixed-methods; public insecurity, collective efficacy, quality of life.

\section{Acknowledgement}

The research findings in this article are taken from a 2016 survey on fear of crime in inner Sydney funded by the City of Sydney and conducted by the University of Sydney. The authors acknowledge Professor Nigel Balmer's valuable input into earlier analysis of the data discussed here. 


\section{Introduction}

Since the 'discovery' of fear of crime, reducing worry about crime has proven a significant issue for policy makers, police and academics (Lee \& Mythen, 2018). Despite falling levels of reported crime in many western nations in recent decades (Farrell, Tilley, \& Tseloni, 2014), levels of fear of crime have tended to decrease at slower rates - if indeed they have reduced at all (Lee, 2007; Simon, 2018). This is concerning because worries and anxieties associated with the fear of crime can erode quality of life and well-being (Jackson \& Stafford, 2009; Stafford, Chandola, \& Marmot, 2007), motivate costly but not always beneficial precautions and restrict movement (Lee, 2007), encourage 'flight' from deprived areas, harm social trust, inter-group relations and the capacity of communities to exercise social control (Hale, 1996; Jackson \& Stafford, 2009), and contribute to a range of 'negative cognitive (pessimism, problem exaggeration) and affective consequences (emotional discomfort, depression)' (Gray, Jackson, \& Farrall, 2011, p. 77). At the same time, fear of crime can shape the machinations of the justice system, the way we treat crime, and those we criminalise (Lee, 2007). Considerable resources are allocated to crime prevention strategies in an effort to reduce fear of crime (Sakip, Joharia, \& Sallehb, 2012), and public institutions such as the police (and all levels of government) develop Key Performance Indicators based on reducing such fears (Lee, 2007). Efforts to reduce worry about crime have increasingly fallen upon local government in Australia, the United Kingdom and other Western nation states (eg. UK Government 2015). Yet, there has been a good deal of contention on how fear of crime has been measured and whether poor survey and research methods have resulted in an overestimation of levels of fear of crime (Farrall, Bannister, Ditton, \& Gilchrist, 1997; Gray, Jackson, \& Farrall, 2008a; Gray et al., 2011; Jackson \& Gray, 2010).

As a methodological response, scholars have recently attempted to more accurately calibrate measures of fear of crime and better define and separate its key concepts and components (Gray et al., 2011). This includes a more granular assessment of worry through measures of frequency of worry and intensity of worry (Gray et al., 2011). Importantly to the current study, researchers have also sought to establish whether respondents' fears are rendered 'functional' or 'dysfunctional' depending on their behavioural and quality of life outcomes (Jackson \& Gray, 2010). Here we draw on Jackson and Gray's (2010) model of functional fear to differentiate between diffuse, affective representation of personal crime risk and the lived experience of anxiety, worry and fear about being victimized in one's daily life. The aim is to better understand the variables likely to predict higher levels and intensity of worry, and importantly, to draw conclusions about how that worry can be managed functionally.

We begin with a critical overview of research into perceptions of crime. We then discuss more recent conceptual and methodological innovations and draw on these for the present study conducted in inner Sydney. We discuss our own methods and present the results and analysis of the research. We conclude with a discussion of the implications of this research to policies of fear reduction.

\section{Criticism of Fear of Crime Research}

Criticism of fear of crime research has long been a feature of the field, crystalising over the years in authoritative periodic literature reviews (DuBow, McCabe, \& Kaplan, 1979; Ferraro \& LaGrange, 1987; Hale, 1996) and compendiums (Ditton \& Farrall, 2000; Farrall, Jackson, \& Gray, 2009; Lee \& Farrall, 2009; Lee \& Mythen, 2018). A surprising amount of the prodigious body of research into fear of crime contests the theoretical and methodological validity and reliability of standard survey tools. Researchers continue to challenge 'misspecifications', both theoretical and empirical, commonly involved in such research (Ditton \& Farrall, 2000; Ferraro \& LaGrange, 1987; Garofalo \& Laub, 1978; Gray et al., 2011; Hale, 1996). Theoretical under-specification has limited the depth and breadth 
of definitions and explanations of fear of crime, leaving us with a 'contested and congested concept' (Gray, Jackson, \& Farrall, 2008b, p. 2) see also (Loader, Girling, \& Sparks, 2000). At the same time, methodological limitations pose serious implications for the validity of the body of knowledge that public policy relies upon (Bernard, 1992; Farrall \& Gadd, 2004; Gray et al., 2008a; Lee, 1999, 2001, 2007; Skogan, 1981). Potentially most troubling is that the technical problems that have dogged this field of inquiry (Ditton \& Farrall, 2000; Farrall et al., 2009; Gray et al., 2008a; Hale, 1996; Lee, 2007; Lee \& Farrall, 2009; Warr, 2000) have impeded the ability to make useful generalisations (Ferraro \& LaGrange, 1987).

Farrall et al. (2009) have shown across a range of measures that many surveys over-estimate the level of everyday worry about victimization, giving us sub-optimal data from which good perceptions of safety policy interventions can be built. For example, most surveys do not tell us about the frequency of respondent's fearful or concerned episodes, nor where these episodes take place. Many questions that are regularly used in surveys, such as 'how safe do you feel walking alone in your neighbourhood after dark?' and 'how worried are you about being attacked in the street by a stranger after dark?', seem to elicit frightening images of people, places and events in respondent's minds, encouraging expressions of fear of crime, often irrespective of (a) whether they ever actually find themselves in such situations and (b) whether they ever actually feel worried and/or fearful (Gray et al., 2008a). This has the potential to exaggerate the expressed concerns that surveys seek to understand or report upon (Hollway \& Jefferson, 2000; Lee, 2007).

There remains an uneasy methodological compromise between the continued use of survey questions that provide a longitudinal perspective on fear of crime and recent methods that provide more nuanced responses to questions about fear of crime (Lee \& Ellis, 2018). Ditton, Farrall, Bannister, \& Gilchrist's (2000) analysis of responses to the question - 'Could you tell me how worried you are about having your home broken into and something stolen?', determined that out of a sample of over 1,000 interviewees, only one was 'really' worried, with a caution that how many respondents could be deemed 'worriers' was a matter of methodological choice, rather than a matter of fact (Ditton et al., 2000). Ditton et al. (2000) also found that almost a third of a sample responded differently to an almost identical version of the same question within half an hour (Ditton et al., 2000). Their suggestion, however, was not to complain about 'response inconsistency' but rather to be more methodologically innovative and give respondents points for worry, thereby creating a 'worry as a continuum', rather than as a dichotomous variable (Ditton et al., 2000). In short, to attempt to represent worry as the complex phenomenon that it is. They emphasise that worry is a matter of degree that represents not a single policy problem of 'fear', but different degrees of a problem, and importantly, probably different problems altogether (Ditton et al., 2000).

In conjunction with these methodological considerations is the ongoing debate over 'fear' of crime vocabulary. Ditton et al. (2000) found in over a decade of fear of crime research that 'fear' about the prospect of, and the reality of criminal victimisation, is secondary to 'anger' about such fears (Ditton et al., 2000) (see also Farrall, 2004). This raises the related concern of the predominance of quantitative research in this field at the expense of more targeted qualitative research (Ditton et al., 2000; Lee \& Ellis, 2018). Fear of crime is researched chiefly by survey instruments, which are often uncritically 'filched' from other such surveys. While 'fear of crime' may affect quality of life, to what extent and why, within certain populations, needs to be investigated further to go beyond 'global' summaries (Gray et al., 2008a, p. 364) and provide more nuanced data to better serve as the basis for tailored fear of crime interventions.

\section{The current study, and trends in fear of crime research}

This study employs many of the key recent advances in both the conceptualisation of fear of crime and the methodologies used to assess it. In particular, it draws on the call from Ditton et al (2000) for 
a more granular assessment of worry through measures of frequency and intensity, whether respondents' fears are 'functional' or 'dysfunctional', and the relationship between measures of collective efficacy, neighbourhood disorder, and informal social control. In this section we explain these concepts further.

Gray et al (2008a) have argued for the inclusion of 'everyday emotions' into such research, while Gerber, Hirtenlehner and Jackson (2010) have differentiated between the affective, cognitive and conative when evaluating personal attitudes towards crime:

"Affective relates to the emotional reaction to crime, cognitive refers to personal risk assessment, and conative is concerned with protective and avoidance behaviour. Feelings, thoughts and behaviours are also assumed to interact. For example, someone may assess a situation as dangerous (cognitive aspect) when coping skills are judged as inadequate; they may then experience an emotion of fear regarding the situation (affective aspect), and they may then react in a defensive manner (conative aspect)." (Gerber et al., 2010: 143)

In response to the lack of instruments that capture the cognitive and behavioural processes involved in the construction of emotional responses to fear of crime Gray et al. (2011) developed a more comprehensive understanding of how crime-emotions affect the ways 'individuals navigate their social worlds and respond to external stimuli' (Gray et al., 2011, p. 76). Through an ordinal measure they locate emotional and behavioural responses to crime on a scale, disentangling 'emotional and behavioural corollaries of crime fears' at an aggregate level (Gray et al., 2011, p. 90); providing opportunities to understand on a large-scale, 'complex patterns of emotional and behavioural responses to public insecurity' (Gray et al., 2011, p. 90).

\section{Defining Feelings}

Gray et al's (2011) definition of fear of crime integrates two conceptual developments. The first distinguishes between 'everyday worries' about crime and more 'diffuse anxieties' about crime (Gray et al., 2011, p. 90) see also (Farrall et al., 2009). 'Worry' involves 'concrete mental events of concern'; while 'anxiety' involves 'a more diffuse mental state' (Gray et al., 2011, p. 76) - a state that Hough has described as 'a rumbling state of unease' (Hough, 2004, p. 174). Through measuring intensity of crime fears and their frequency, Gray et al. (Gray et al., 2011) attempted to isolate memorable events of everyday worries from 'emotionally-tinged' attitudes towards risk or 'futureoriented anxiety' expressed through being more troubled generally by the risks of being victimised (Gray et al., 2011, p. 76). A 'raw count' of worrying events is counted over a narrow timeframe to minimise telescoping and generate more accurate recall 'of situated and concrete moments of concern' (Gray et al., 2011, p. 77). Gray et al. (2011) argue that the frequency questions capture 'experiences' of worry about crime, while standard questions are more likely to measure aspects of anxiety - including broader attitudes or judgements about crime (Gray et al., 2011). Combining the standard (intensity) and frequency measures differentiated between the 'unworried' - who reported being 'unworried' on both measures, and the 'worried', who worried on the standard question but who when asked the frequency question could not recall a recent event of worry (Gray et al., 2011). The 'unworried' were the most common grouping on both measures, and the most interesting category was the 'anxious', who said they were worried about a particular crime but were unable to recall a recent episode of worry (Gray et al., 2011). These 'anxious' individuals 'described an emotional experience that was more diffuse and more intangible than any memorable or conspicuous event' (Gray et al., 2011, p. 77). 


\section{Defining functions}

The second conceptual development is functional fear (Jackson \& Gray, 2010; Warr, 2000), which distinguishes between the 'functional' and 'dysfunctional' effects of everyday worries and anxieties (Gray et al., 2008a, 2011). Consistent with the ways in which worry can positively motivate, Jackson and Gray (2010) found that a significant minority of individuals who said they were worried about crime also reported that they took precautions--that made them feel safer--and that neither their precautions nor their worries about crime affected their quality of life (Gray et al., 2011). In such contexts, 'fear' might better viewed as a functional defence against crime because it motivates socially beneficial behaviour - something that allows individuals to exert control over perceived risks and to stimulate action, rather than an inherently negative feeling that erodes quality-of-life. Worry can thus serve a motivational and precautionary function, helping to prepare for threat by prompting 'adaptive vigilance and routine precaution' (Gray et al., 2011, p. 77).

Yet, worry is certainly not always functional. Among the features of 'high' worriers were more frequent episodes of worry (at least daily); greater difficulty in stopping worrying; rebounding worries; and mood disturbance and perceived impairment in everyday functioning (Gray et al., 2011). In their research, 'high' worriers also reported greater indecision and doubt when worrying, and they were more likely to perceive worry as having a negative effect on their health (Gray et al., 2011). So Gray et al. (2011) then combined these distinctions into an ordinal scale that moves from the 'unworried', to low-level motivating emotions, to frequent and dysfunctional worry about crime:

- Unworried

- Anxious - functional

- Worried - functional

- Anxious - dysfunctional

- Worried - dysfunctional

Gray et al.'s 2011 study found that $27 \%$ of the sample fell into the dysfunctional category (compared to $8 \%$ in the functional category) (Gray et al., 2011). The odds ratio for 'dysfunctionally worried' was considerably larger for respondents who had been victimised over the past 12 months (Gray et al., 2011).

The present study makes use of the 'everyday worries' development by using targeted questions that tap into this 'experiential fear' rather than more diverse anxieties (Jackson \& Kuha, 2016). In terms of concrete questions to more accurately measure fear of crime, and even the precautionary benefits of fear of crime, we follow Gray et al. (2008a) model for a series of questions that:

1. Measure worry about crime using a standard intensity measure and frequency

2. Include supplementary questions that gauge the precautions taken by the worried respondents, and

3. Measure the impact that taking these precautions had on the respondents' quality of life and feelings of safety.

\section{Fear of crime and victimisation}

The evidence on the role of previous victimisation in fear of crime is still mixed although many studies have drawn a strong association (Bernard, 1992; Hale, 1996; Lee, 2015; Russo \& Roccato, 2010). Moreover, there are questions about how differences in perceptions of crime victimisation and risk correlate with inter-individual variations in socio-demographic characteristics, routine activities, 
and contextual factors and judgement of risk (Hale, 1996). Jackson and Stafford (2009) suggest that the association between prospective fear of crime and mental health problems contributes to a 'recursive' model of fear and health, with the mental health problems leading to a further increase in fear of crime (Jackson \& Stafford, 2009). Also, that 'victimisation experience is related to dysfunctional worry but not with functional worry, and that social concerns (about neighbourhood disorder and levels of collective efficacy) are associated with both functional and dysfunctional worry about crime' (Jackson \& Gray, 2010, p. 2). Hale (1996) suggests that while 'neutralisation techniques' employed by some victims of crime motivate them to become more cautious or employ strategies to prevent further victimisation, that the related variable of 'indirect victimisation' actually allows 'one's imagination full scope without perhaps the same urgency to find a coping strategy' (Hale, 1996, p. 105). This may explain why the indirectly victimised sometimes report higher levels of fear of crime than those actually victimised. The current study includes questions on victimisation in an effort to assess its influence on our sample.

\section{Informal social control and collective efficacy}

The formal agents of social control such as public police are not 'omnipresent' within or across communities and neighbourhoods (Sargeant, 2017). The control of the streets and neighbourhoods is much more a function of residents and community members, in conjunction with police, security guards and other formal agents of social control (Sargeant, 2017).

The related concept of 'collective efficacy' has emerged from this interest in community dynamics, circumstances and crime (Sampson 2004; Wikes et al. 2018). According to Sampson (2004), neighbourhood collective efficacy 'captures the link between cohesion - especially working trust - and shared expectations for action' (Sampson 2004, p. 108). More specifically, 'a neighbourhood's efficacy exists relative to specific tasks such as maintaining public order. The key causal mechanism in collective efficacy theory is social control enacted under conditions of social trust' (Sampson 2004 p 108). Thus, collective efficacy is the neighbourhood's ability to maintain order in public spaces such as streets, footpaths and parks (Vold, Bernard, \& Snipes, 2002, pp. 131-2), which raises issues associated with shared expectation and mutual engagement by local residents. Drawing on Sampson's model we have included a range of such measures here (Sampson 2004: Sampson \& Groves 1989).

\section{The Study}

\section{Method}

A total of 409 respondents $(n=409)$ residing in the City of Sydney Local Government Area were randomly selected for this study. Data were collected using Computer Assisted Telephone Interview (CATI). Each interview was approximately 10 to 15 minutes in length. The survey is a refinement of a pilot survey conducted in 2015 in inner-city Sydney, co-funded by the City of Sydney and the University of Sydney. The findings in this article are from the second sweep of the survey, conducted in 2016, and commissioned by the City of Sydney. The study included a qualitative component - 13 focus groups conducted across the City of Sydney Local Government Area. Significantly these groups included a cross section of the community, and notably several hard-to-reach or vulnerable community groups - Cantonese speakers, Serbian speakers, LGBTI young people and international students. We did not have space in this article to include these more detailed and nuanced perspectives on fear of crime (see Lee et al., 2020).

Seven key dimensions from the contemporary perceptions of crime research discussed above are 
drawn upon in this survey:

1. Demographic data aimed specifically to identify variables in perceived vulnerability - age, gender, sexuality, ethnicity

2. The relative seriousness of various kinds of neighbourhood disorder

3. Level of collective efficacy at the neighbourhood level (how supportive the local community was perceived to be and how trustworthy neighbours were)

4. Perceived level of informal social control in the area (how reliable were neighbours/community in dealing with the possibility of offending behaviours)

5. How worried respondents were about being a victim of a range of offences (burglary, harassment in public, being sexually assaulted in public, and being physically assaulted in public) and how frequently in the past year respondents (if at all) had worried about the possibility of being victimised

6. Avoidance behaviours and whether such behaviour negatively affected quality of life; this allowed us to test whether fear was functional or dysfunctional in relation to behavioural patterns

7. Past victimisation.

\section{Sample}

The data was weighted on the basis of age and gender to reflect the population of the City of Sydney using 2011 Australian Bureau of Statistics Census of Population and Housing data. The demographic profile of the sample $(n=409)$ is as follows

- Gender - 196 (47.9\%) were male and 213 (52.1\%) female;

- Age - 44 respondents were aged 18-24 (10.8\%), 119 (29.1\%) aged 25-34, 151 (36.9\%) aged 35-49, 43 (10.5\%) aged 50-59, 23 (5.6\%) aged 60-69 and 29 (7.1\%) aged 70 or older;

- Sexual orientation - 331 of 409 respondents (80.9\%) identified as heterosexual, with 43 $(10.5 \%)$ identifying as gay, $8(2.0 \%)$ identifying as lesbian, $12(2.9 \%)$ as bisexual, $4(1.0 \%)$ as queer, 3 respondents $(0.7 \%)$ identified as other and $8(2.0 \%)$ preferred not to say;

- Nationality - 237 of the 409 respondents (57.9\%) were born in Australia, with the remainder covering a very broad range of countries. Of the 237 Australian born respondents, 7 (3.0\%) identified as Aboriginal or Torres Strait Islander; a further two preferred not to say;

- Relationship status - 200 of 409 respondents were married or living with a partner (48.9\%). $206(50.4 \%)$ were not married or living with a partner and a further three proffered not to respond;

- Parental status - 111 of 409 (27.1\%) were parents. 53 of these parents (47.7\%) currently had a child under 18 years of age;

- Employment - 238 respondents of the sample (58.2\%) were in full-time employment. There were also 55 respondents in part-time employment (13.4\%), $9(2.2 \%)$ in home duties, 7 $(1.7 \%)$ in intermittent employment, 17 unemployed $(5.1 \%$ - of whom 14 were looking for work), $2(0.5 \%)$ unable to work, 37 (9.0\%) retired, 20 (4.9\%) domestic students, 21 (5.1\%) international students and $2(0.5 \%)$ unpaid intern/volunteers, as well as a single respondent $(0.2 \%)$ choosing not to respond; and,

- Education - 4 of 409 (1.0\%) suggested that primary school was their highest education level, 69 (16.9\%) secondary, 24 (5.9\%) TAFE certificate I/II, 14 (3.4\%) TAFE certificate III/IV, 48 (11.7\%) diploma/advanced diploma, 125 (30.6\%) bachelor degree, 24 (5.9\%) graduate diploma/certificate, $99(24.2 \%)$ postgraduate degree and $2(0.5 \%)$ other. 


\section{Measures and descriptive statistics}

Table 1 provides the wording and descriptive statistics of the key measures. Respondents were asked whether or not in the last year they had worried about their home being burgled, being harassed in public, being physically assaulted in public or being sexually assaulted in public. If respondents said 'yes', they were then asked the number of times they had felt like this in the last year. A total of $29 \%$ reported having felt worried about being burgled, 27\% about being harassed, 19\% about being physically assaulted, and 7\% about being sexual assaulted. Overall, 199 of 409 (49\%) reported worrying about one or more of the four in the past year. There was a sizable minority $(13 \%)$ who indicated that they have some worry about a category of crime every week of the year or more. Indeed, two respondents suggested they worry 365 days of the year.

Table 1. Items and measures descriptive statistics.

\begin{tabular}{|c|c|c|c|c|c|}
\hline & $M$ & $S D$ & Min & $\operatorname{Max}$ & $\boldsymbol{\alpha}$ \\
\hline \multicolumn{6}{|l|}{ Worry about crime } \\
\hline $\begin{array}{l}\text { In the last year have you ever felt worried about your home being burgled (broken into)? } \\
\text { No (0), yes (1) }\end{array}$ & .29 & & 0 & 1 & \\
\hline if yes, how frequently have you felt like this in the last year? [insert raw frequency] & 11.47 & 53.11 & 0 & 365 & \\
\hline In the last year have you ever felt worried about being harassed in public? No (0), yes (1) & .28 & & 0 & 1 & \\
\hline if yes, how frequently have you felt like this in the last year? [insert raw frequency] & 15.42 & 61.86 & 0 & 365 & \\
\hline $\begin{array}{l}\text { In the last year have you ever felt worried about being physically assaulted in public? No } \\
(0) \text {, yes (1) }\end{array}$ & .18 & & 0 & 1 & \\
\hline if yes, how frequently have you felt like this in the last year? [insert raw frequency] & 5.84 & 38.79 & 0 & 365 & \\
\hline $\begin{array}{l}\text { In the last year have you ever felt worried about being sexually assaulted in public? No } \\
(0) \text {, yes (1) }\end{array}$ & .07 & & 0 & 1 & \\
\hline if yes, how frequently have you felt like this in the last year? [insert raw frequency] & 2.17 & 20.76 & 0 & 365 & \\
\hline \multicolumn{6}{|l|}{ Precautions against crime } \\
\hline \multicolumn{6}{|l|}{$\begin{array}{l}\text { How often [if at all] in the last year have you taken the following precautions against crime } \\
\text { in your local area? Would you say never (0), occasionally (1), sometimes (2), most of the } \\
\text { time (3) or always (4)? }\end{array}$} \\
\hline avoided using public transport during the day & .94 & .45 & 0 & 4 & \\
\hline avoided using public transport at night & .69 & 1.17 & 0 & 4 & \\
\hline avoided certain streets or areas during the day & .34 & .83 & 0 & 4 & \\
\hline avoided certain streets or areas at night & 1.39 & 1.37 & 0 & 4 & \\
\hline carried some means of self-defence & .32 & .93 & 0 & 4 & \\
\hline \multicolumn{6}{|l|}{ Effect on quality of life } \\
\hline $\begin{array}{l}\text { Overall, how much [if at all] is your quality of life negatively affected by worries about } \\
\text { becoming a victim of crime? Would you say not at all (1), a little (2), moderately (3), quite } \\
\text { a bit (4) or very much (5)? }\end{array}$ & 1.71 & .99 & 1 & 5 & \\
\hline $\begin{array}{l}\text { Overall, how much [if at all] is your quality of life negatively affected by the precautions } \\
\text { you take against crime? Would you say not at all (1), a little (2), moderately (3), quite a bit } \\
\text { (4) or very much (5)? no precautions against crime coded as (1) }\end{array}$ & 1.56 & .91 & 1 & 5 & \\
\hline \multicolumn{6}{|l|}{ Direct victimization experience } \\
\hline I have been burgled (broken into) in the last year & .05 & & 0 & 1 & \\
\hline I have been insulted or harassed in public in the last year & .25 & & 0 & 1 & \\
\hline I have been physically assaulted in public in the last year & .05 & & 0 & 1 & \\
\hline I have been sexually assaulted in the last year & .01 & & 0 & 1 & \\
\hline \multicolumn{6}{|l|}{ Indirect victimization experience } \\
\hline Someone I know has been burgled (broken into) in the last year & .32 & & 0 & 1 & \\
\hline Someone I know has been insulted or harassed in public in the last year & .41 & & 0 & 1 & \\
\hline Someone I know has been physically assaulted in public in the last year & .23 & & 0 & 1 & \\
\hline Someone I know has been sexually assaulted in the last year & .08 & & 0 & 1 & \\
\hline Perceived disorder (index of saved component scores) & $\mathbf{0}$ & .84 & -1.12 & 2.11 & .73 \\
\hline $\begin{array}{l}\text { Now I would like to ask you some questions about your neighbourhood. I will read out a list } \\
\text { of issues that may or may not be a problem in your area. For each one please tell me whether }\end{array}$ & & & & & \\
\hline
\end{tabular}




\begin{tabular}{|c|c|c|c|c|c|}
\hline \multicolumn{6}{|l|}{ it is a major problem (2), a minor problem (1) or no problem (0). [order was randomized] } \\
\hline graffiti & .61 & .66 & 0 & 2 & \\
\hline vandalism, for instance of telephone booths or bus shelters & .52 & .61 & 0 & 2 & \\
\hline noisy and/or nuisance neighbours & .65 & .71 & 0 & 2 & \\
\hline noisy/rowdy/inconsiderate behaviour in the street & .83 & .73 & 0 & 2 & \\
\hline teenagers hanging around in the street & .46 & .66 & 0 & 2 & \\
\hline Perceived collective efficacy (index of saved component scores) & $\mathbf{0}$ & .89 & -2.98 & 1.73 & .80 \\
\hline \multicolumn{6}{|l|}{$\begin{array}{l}\text { Using a scale of strongly disagree (1), disagree (2), neither agree nor disagree (3), agree (4) } \\
\text { and strongly agree (5), please tell me how much you agree or disagree with each of the } \\
\text { following statements. [order was randomized] }\end{array}$} \\
\hline people around here are willing to help their neighbours & 3.63 & 1.02 & 1 & 5 & \\
\hline this is a close-knit neighbourhood & 3.12 & 1.18 & 1 & 5 & \\
\hline people in this neighbourhood can be trusted & 3.55 & .97 & 1 & 5 & \\
\hline $\begin{array}{l}\text { if I sensed trouble while in this area, I could 'raise' attention from people who live here for } \\
\text { help }\end{array}$ & 3.83 & .93 & 1 & 5 & \\
\hline $\begin{array}{l}\text { the people who live here can be relied upon to call the police if someone is acting } \\
\text { suspiciously }\end{array}$ & 3.79 & 1.04 & 1 & 5 & \\
\hline $\begin{array}{l}\text { if any of the children or young people around here are causing trouble, local people will } \\
\text { tell them off }\end{array}$ & 3.20 & 1.09 & 1 & 5 & \\
\hline
\end{tabular}

Figure 1 breaks down worry about each of the four crime types by gender. While males (31\%) are slightly more likely than females $(26 \%)$ to worry about having their home burgled, women $(32 \%)$ worried more about being harassed in public than men $(23 \%)$ and being sexually assaulted (females $13 \%$, males 1\%). There were no significant gender differences in levels of worry about being assaulted in public with $20 \%$ of males and $19 \%$ of females expressing being worried about this in the past 12 months.

Figure 1. Percentage of respondents feeling worried and not worried in the past 12 months by gender and crime type.

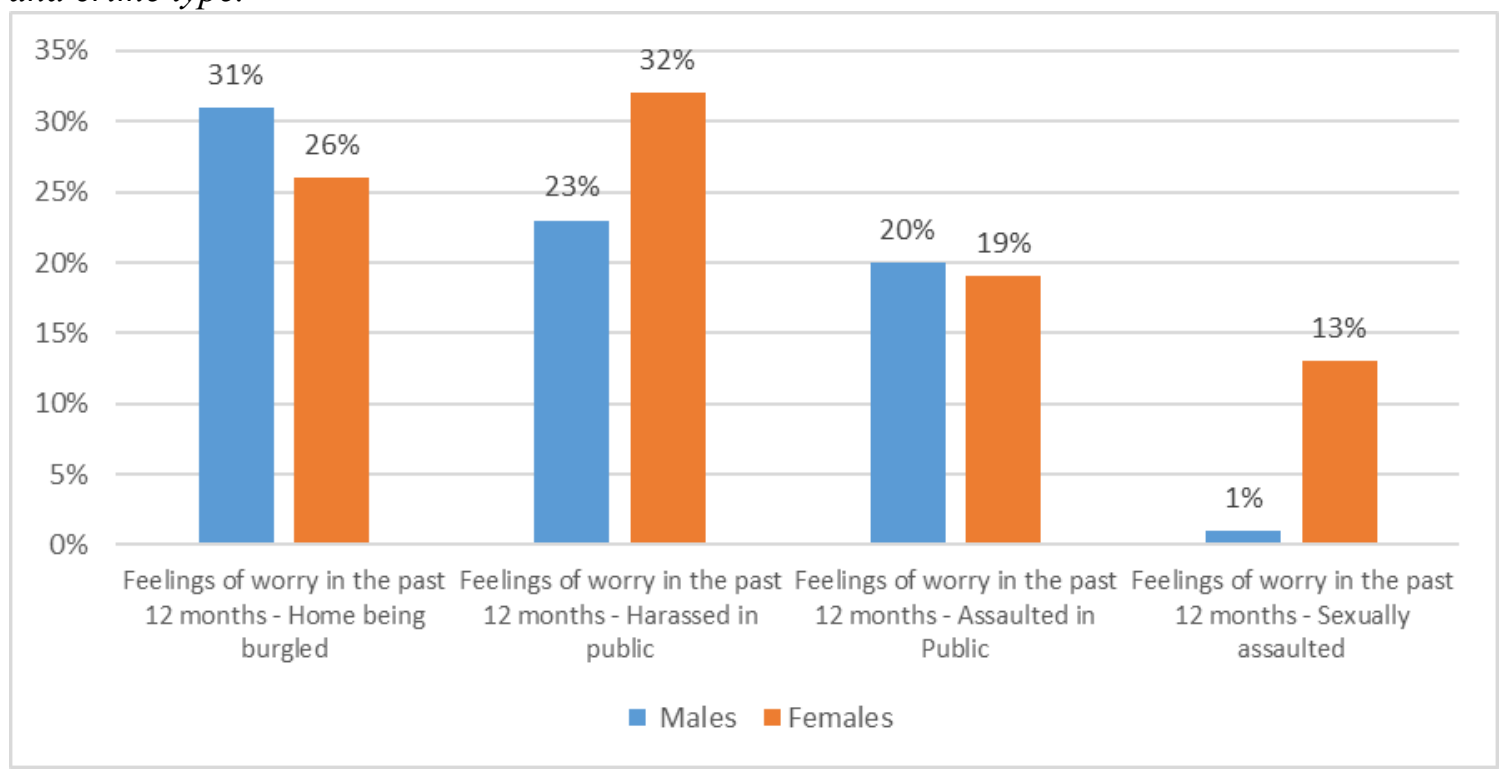

Figure 2 provides a breakdown of whether someone had indicated worrying about at least one crime type by age. While the younger age group were more likely to express worry, perhaps because they are more likely to be in public places at night, there was little overall variation. A small sample size in the $70+$ category should exclude it. 
Figure 2. Percentage worried and not worried in the past 12 months by age group.

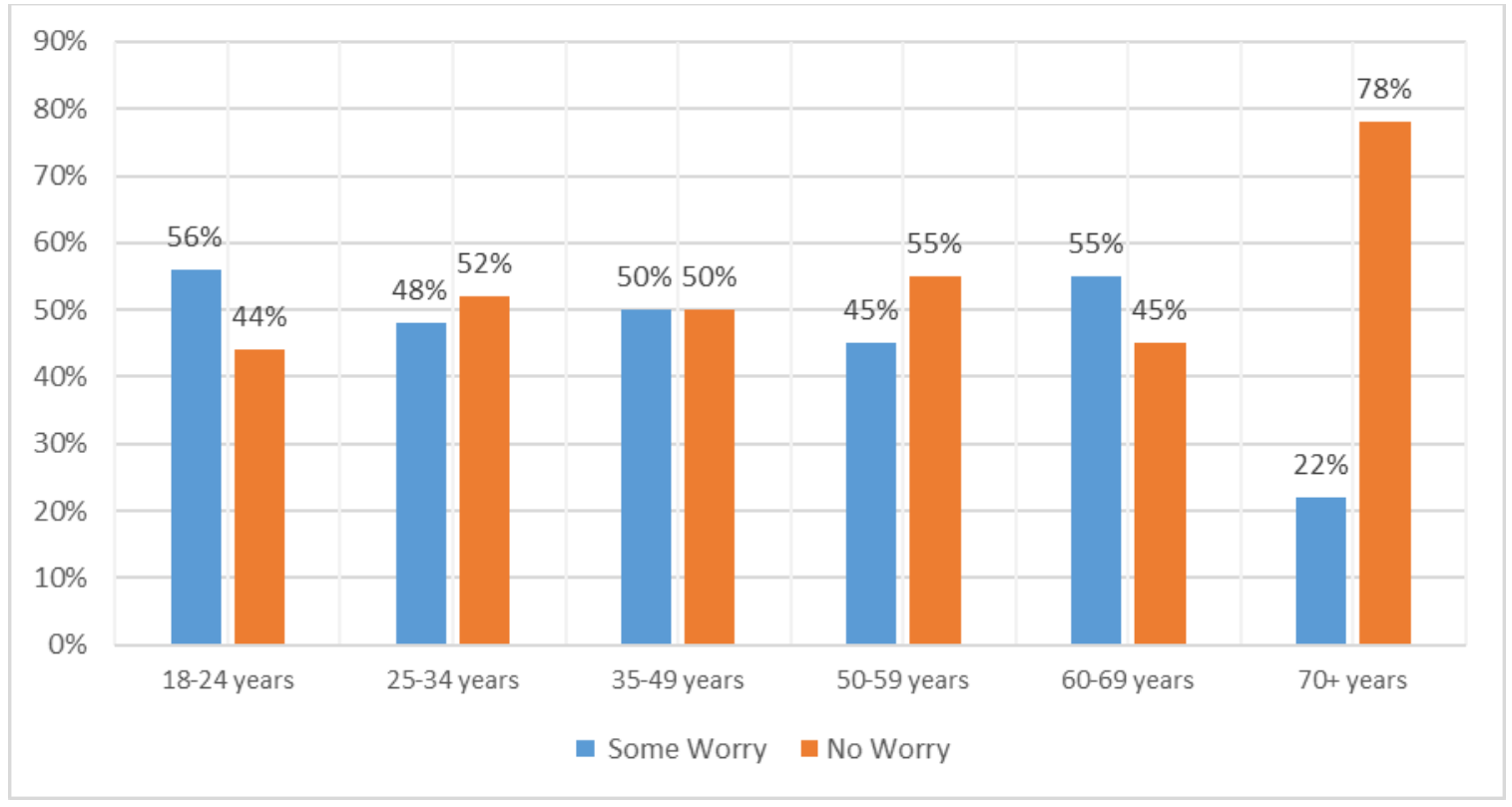

Respondents were asked how often (if at all) they had taken a range of precautions against crime in their local area in the past year (Table 1). Avoiding certain streets/areas at night (42\%) proved the most common avoidance strategy, and avoiding public transport at night (18\%) the second most common avoidance strategy. Respondents were also asked whether they had ever enhanced security in and/or around their home specifically as a precaution against crime. A total of 98 of 409 respondents $(23.9 \%)$ suggested that they had, with 38 (9.4\%) having done so in the past year. Those who had taken one of the crime avoidance precautions, or had enhanced their home security in the past year were asked the extent to which they felt safer as a consequence. Of the 287 (70\%) who had taken some form of precaution, 21 (7\%) suggested they felt 'Not at all' safer, $46(16 \%)$ 'A little' safer, 69 (24\%) 'Moderately' safer, 64 (23\%) 'Quite a bit' safer, 57 (20\%) 'Very much' safer with a further $27(10 \%)$ unsure.

Respondents were also asked about the extent to which their quality of life had been affected by worry about becoming a victim of crime (asked of all respondents) or precautions they had taken against crime (asked of those who took precautions), with responses shown in Table 2. Of those that worried $52 \%$ said this worry did not negatively affect their quality of life. Similarly, of those that took precautions some $46 \%$ thought such precautions did not negatively affect their quality of life. What this indicates is that we need to be mindful in thinking worry about crime is always a negative issue. This is taken up in the results section on functional fear.

Table 2. The extent to which respondents felt that their quality of life had been affected by worry about becoming a victim of crime (asked of all respondents) or precautions they had taken against crime (asked of those who took precautions).

\begin{tabular}{|c|c|c|c|c|c|}
\hline & $\begin{array}{l}\text { Worries about } \\
\text { becoming a victim }\end{array}$ & $\begin{array}{l}\text { Precautions taken } \\
\text { against crime }\end{array}$ & & & \\
\hline & Frequency & Total $\%$ & Frequency & $\begin{array}{c}\% \text { of all } \\
\text { respondents }\end{array}$ & $\begin{array}{l}\% \text { of those who } \\
\text { took precautions }\end{array}$ \\
\hline Not at all & 214 & $52 \%$ & 132 & $32 \%$ & $46 \%$ \\
\hline A little & 127 & $31 \%$ & 95 & $23 \%$ & $33 \%$ \\
\hline Moderately & 41 & $10 \%$ & 34 & $8 \%$ & $12 \%$ \\
\hline Quite a bit & 12 & $3 \%$ & 12 & $3 \%$ & $4 \%$ \\
\hline
\end{tabular}




\begin{tabular}{|l|c|c|c|c|c|}
\hline Very much & 13 & $3 \%$ & 8 & $2 \%$ & $3 \%$ \\
\hline Don't know & 2 & $1 \%$ & 6 & $1 \%$ & $2 \%$ \\
\hline Total & 409 & $100 \%$ & 287 & $70 \%$ & $100 \%$ \\
\hline
\end{tabular}

Respondents were asked whether they, or someone they knew had been a victim of one of the four forms of crime in the past year. While a small number of respondents had been victimised over the past year, almost $25 \%$ reported being insulted or harassed in public (Table 1). Respondents were also asked whether they felt that six type of neighbourhood problem were a major problem, minor problem or not a problem in their area. 'Noisy/rowdy behaviour on the street' topped the list with $64 \%$ in total seeing it as problem in their area and $20 \%$ of these reporting that it was a major problem (Table 1). Finally, respondents were asked three questions that aimed to measure collective efficacy and three other questions designed to measure social control in their area. While responses to these questions indicate generally favourable views of local community and local neighbourhood, respondents were less likely to agree that 'if children/young people are causing trouble local people will tell them off' and that the neighbourhood is 'close-knit' (Table 1).

\section{Results}

Our focus here is on functional and dysfunctional fear of crime. We (a) test whether Jackson \& Gray's (2010) and Gray et al.'s (2011) categorization holds with the Sydney data and (b) examine key predictors with a particular focus on gender, age, direct and indirect victimization experience, perceived disorder and perceived collective efficacy.

As described earlier, functional fear can be thought of as a natural, functional defence against crime involving straightforward adaptations and behaviours - 'a potentially socially beneficial activity that allows individuals to exert control over perceived risks, encouraging them to behave in a responsible fashion' (Gray et al., 2011, p. 78). It may even be pro-social in nature with the capacity to activate group rather than individual responses to worry. Functional fear is when people report being worried about crime ( $49 \%$ of respondents), take some kind of precaution against crime $(68 \%$ of respondents), feel safer as a result of their precautions (64\% of respondents) and do not think their quality of life is reduced by their worry about crime ( $85 \%$ of respondents) or precautions against crime (67\% of respondents). Among those respondents who said that they had worried at least once about victimisation, $44 \%$ fell into this functional fear category. That is, they took precautions, these precautions made them felt safer as a result, and their worry and precautions did not affect their quality of life in a negative way.

Combining information about the frequency and functionality of worry reveals an interesting picture (Table 3). We can see that $211(52 \%)$ respondents reported that they were not worried about crime. Functional fear was evident among $26(6 \%)$ respondents, and of the remaining respondents who reported dysfunctional fear, $86(21 \%)$ had worried once a month or less, $39(10 \%)$ had worried between once a week and just less than once a month, and $47(12 \%)$ had worried more than once a week. This demonstrates quite a close fit to the results recorded by Gray et al (2011).

Table 3. Constructing the categorization

\begin{tabular}{|l|c|c|}
\hline & $\begin{array}{c}\text { Categories of worry } \\
\text { about crime }\end{array}$ & Total \% \\
\hline Unworried & Frequency & $52 \%$ \\
\hline Functional worry & 211 & $6 \%$ \\
\hline Dysfunctional worry - worried once a month or less & 26 & $21 \%$ \\
\hline Dysfunctional worry - worried between once a week & 86 & $10 \%$ \\
\hline
\end{tabular}




\begin{tabular}{|c|c|c|}
\hline and just less than once a month & & \\
\hline Dysfunctional worry - worried more than once a week & 47 & $12 \%$ \\
\hline Total & 409 & 100.0 \\
\hline
\end{tabular}

The final step of analysis is to assess the extent to which gender, age, direct victimisation experience, indirect victimisation experience, perceptions of community disorder and perceptions of collective efficacy predict category membership. We fit a multinomial logistic regression model, using 'unworried' as the reference category. Table 4 presents the results of this model. As demonstrated, gender and age are unrelated to worry about crime, controlling for perceptions of community disorder, perceptions of collective efficacy, direct victimisation experience and indirect victimisation experience (the exception being that females are more likely than males to fall into the 'dysfunctional worry, more than once a week' category, as opposed to the 'unworried worry' category). An odds ratio of 2.59 means that the odds of being in the 'dysfunctional worry, more than once a week' category compared to the 'unworried worry' category are $159 \%$ more than they are for females compared to males.

Table 4. Multinomial logistic regression predicting membership of six fear of crime groups

\begin{tabular}{|c|c|c|c|c|}
\hline & OR & P -value & $\begin{array}{l}95 \% \text { CI } \\
\text { lower } \\
\text { bound }\end{array}$ & $\begin{array}{l}\text { 95\% CI } \\
\text { upper } \\
\text { bound }\end{array}$ \\
\hline \multicolumn{5}{|l|}{ 'UNWORRIED’ VS 'FUNCTIONAL WORRY' } \\
\hline Female $(0=$ male, $1=$ female $)$ & 2.22 & 0.11 & 0.83 & 5.97 \\
\hline Age $(6$ categories, higher $=$ older $)$ & 1.17 & 0.38 & 0.83 & 1.64 \\
\hline Perceptions of community disorder (high scores $=$ more disorder) & 1.13 & 0.71 & 0.60 & 2.10 \\
\hline $\begin{array}{l}\text { Perceptions of collective efficacy (high scores }=\text { more collective } \\
\text { efficacy) }\end{array}$ & $0.44 * * *$ & 0.00 & 0.25 & 0.76 \\
\hline Direct experience of crime & $3.45^{*}$ & 0.03 & 1.16 & 10.26 \\
\hline Indirect experience of crime & 2.42 & 0.09 & 0.88 & 6.62 \\
\hline \multicolumn{5}{|l|}{ 'UNWORRIED' VS 'DYSFUNCTIONAL =< ONCE A MONTH' } \\
\hline Female $(0=$ male, $1=$ female $)$ & 0.70 & 0.26 & 0.38 & 1.30 \\
\hline Age $(6$ categories, higher $=$ older $)$ & 0.92 & 0.48 & 0.74 & 1.15 \\
\hline Perceptions of community disorder (high scores = more disorder) & 1.17 & 0.43 & 0.79 & 1.74 \\
\hline $\begin{array}{l}\text { Perceptions of collective efficacy (high scores }=\text { more collective } \\
\text { efficacy) }\end{array}$ & 1.23 & 0.30 & 0.83 & 1.80 \\
\hline Direct experience of crime & $3.58 * * *$ & 0.00 & 1.73 & 7.44 \\
\hline Indirect experience of crime & $2.68 * * *$ & 0.00 & 1.44 & 4.97 \\
\hline \multicolumn{5}{|l|}{$\begin{array}{l}\text { 'UNWORRIED' VS 'DYSFUNCTIONAL > ONCE A MONTH'\& } \\
<=\text { ONCE A WEEK' }\end{array}$} \\
\hline Female $(0=$ male, $1=$ female $)$ & 2.01 & 0.12 & 0.84 & 4.82 \\
\hline Age $(6$ categories, higher $=$ older $)$ & 1.23 & 0.18 & 0.91 & 1.66 \\
\hline Perceptions of community disorder (high scores = more disorder) & $2.74 * * *$ & 0.00 & 1.59 & 4.72 \\
\hline $\begin{array}{l}\text { Perceptions of collective efficacy (high scores }=\text { more collective } \\
\text { efficacy) }\end{array}$ & 0.64 & 0.07 & 0.40 & 1.04 \\
\hline Direct experience of crime & $5.69 * * *$ & 0.00 & 2.28 & 14.25 \\
\hline Indirect experience of crime & $3.30 *$ & 0.02 & 1.26 & 8.60 \\
\hline \multicolumn{5}{|l|}{ 'UNWORRIED' VS 'DYSFUNCTIONAL > ONCE A WEEK' } \\
\hline Female $(0=$ male, $1=$ female $)$ & $2.59 *$ & 0.03 & 1.09 & 6.12 \\
\hline Age $(6$ categories, higher $=$ older $)$ & 1.12 & 0.47 & 0.82 & 1.53 \\
\hline Perceptions of community disorder (high scores = more disorder) & $1.96^{* *}$ & 0.01 & 1.16 & 3.29 \\
\hline Perceptions of collective efficacy (high scores $=$ more collective & $0.60^{*}$ & 0.04 & 0.37 & 0.97 \\
\hline
\end{tabular}




\begin{tabular}{|l|l|l|l|l|}
\hline efficacy) & & & \\
\hline Direct experience of crime & $8.76^{* * *}$ & 0.00 & 3.61 & 21.28 \\
\hline Indirect experience of crime & $12.30^{* *}$ & & & 4 \\
\hline
\end{tabular}

Note: $n=347$. OR $=$ adjusted odds ratio, $95 \% C I=95 \%$ confidence interval for the adjusted odds radio. ${ }^{*} p<0.05, * *$ $p<0.01, * * * p<0.001$.

The best way of describing a fitted multinomial logistic model is in terms of fitted response probabilities. Figure 3 shows the fitted probabilities over the range of perceived community disorder (adjusting for the other variables in the model, fixing their levels at their mean). As perceived disorder increases, so the predicted probability of being 'unworried' reduces (from 0.6 and 0.3 ), the predicted probability of being in the 'dysfunctional worry, between once a week and just less than once a month' category increases (from 0.04 to 0.35 ), and the predicted probability of being in the 'dysfunctional worry, more than once a week' category increases (from 0.05 to 0.15 ).

Figure 3. Predicted probability of worry about crime group membership, given levels of perceived disorder

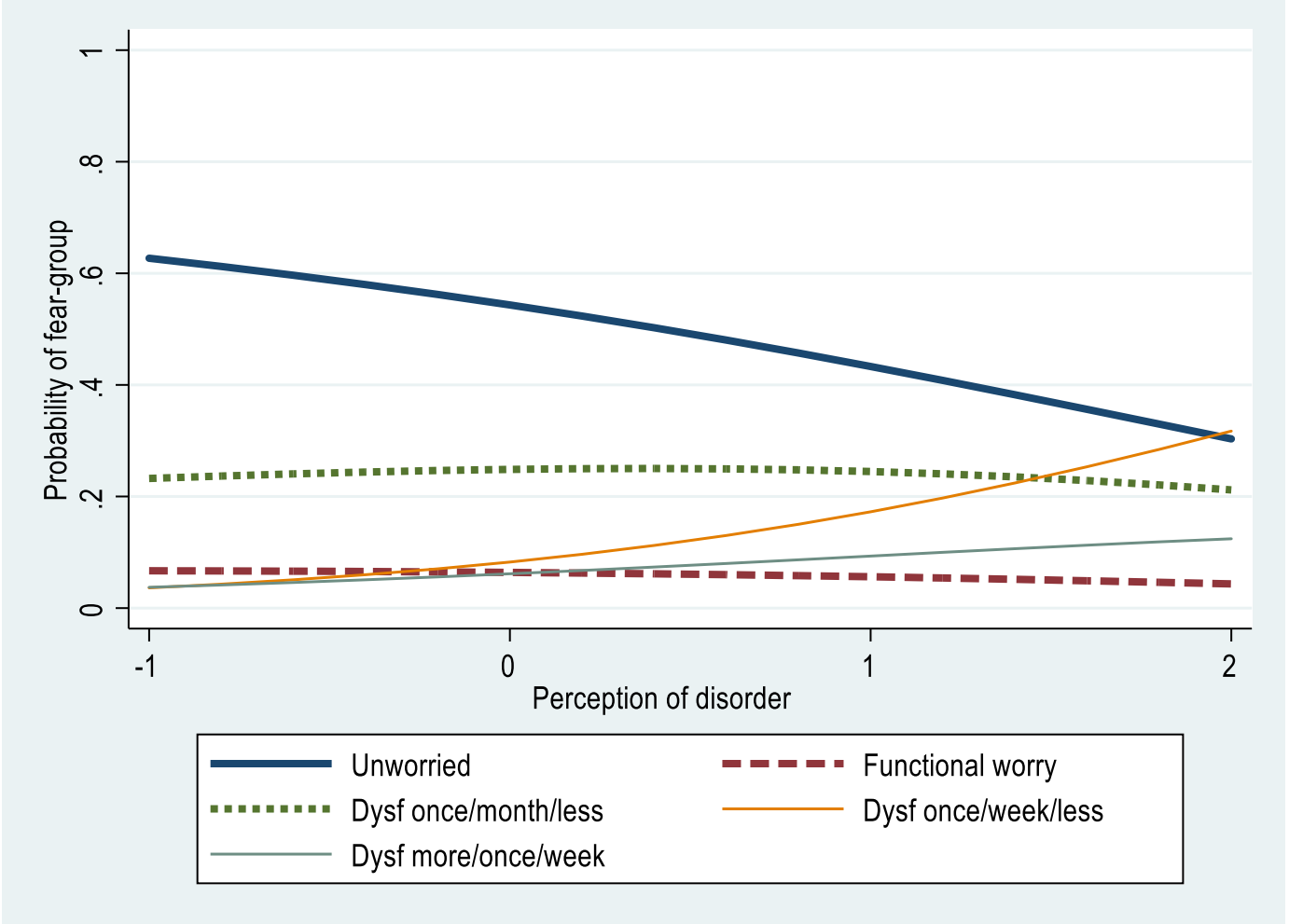

Figure 4 shows the fitted probabilities for perceived collective efficacy (adjusting for the other variables in the model, fixing their levels at their mean). As perceived collective efficacy increases, so the predicted probability of being in one of the more frequent worry groups decreases, while the predicted probability of being in the least frequent worry group increases. 
Figure 4. Predicted probability of worry about crime group membership, given levels of perceived collective efficacy

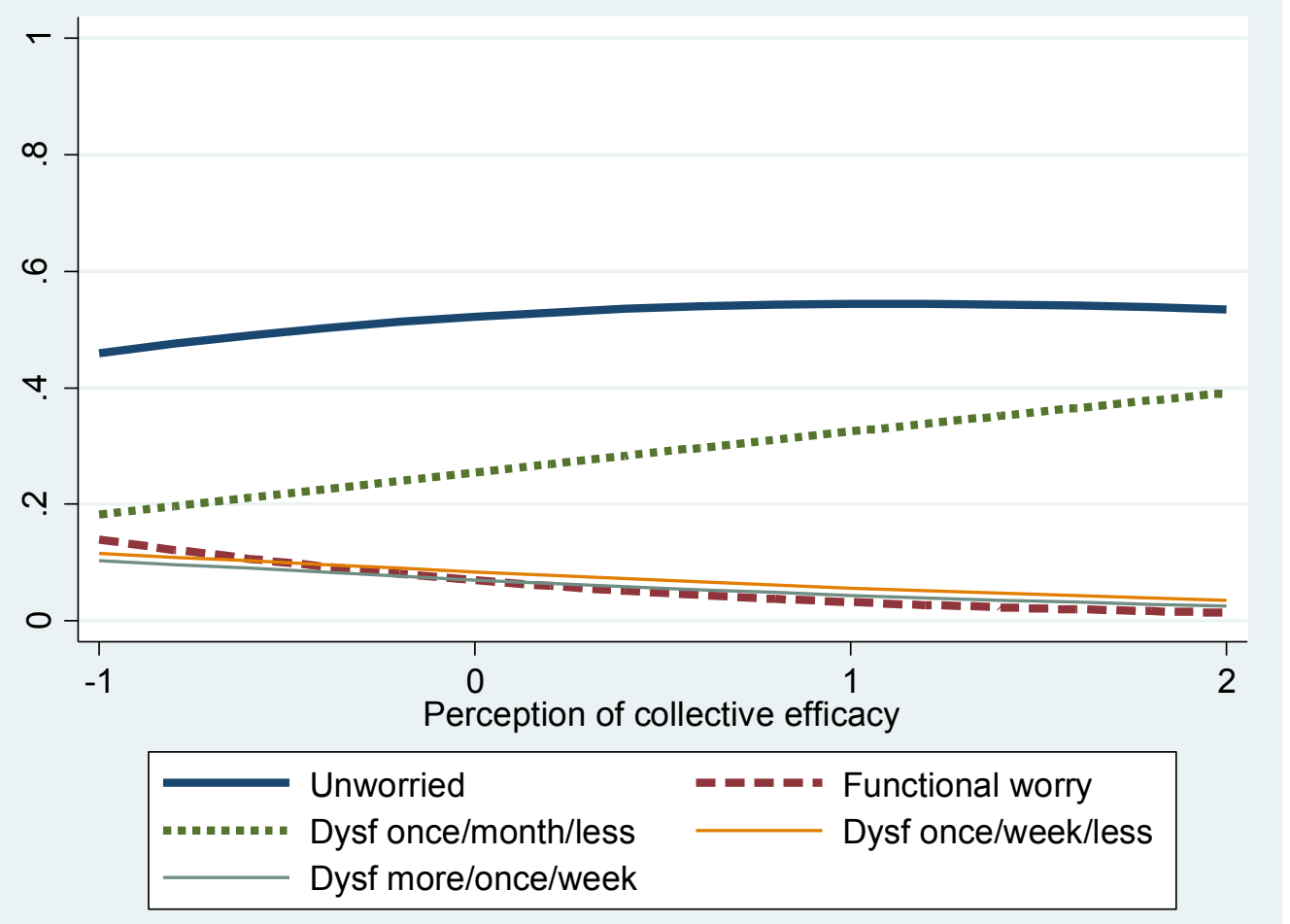

Finally, Tables 5 and 6 present the fitted probabilities for direct and indirect victimisation experience (adjusting for the other variables in the model, fixing their levels at their mean). We show strong statistical effects of victimisation, particularly when it is direct victimisation. For example, the expected probability of being unworried among those people without direct victimisation experience (and controlling for age, gender, perceptions of disorder, perceptions of collective efficacy, and indirect victimisation experience) is 0.63 , while the comparable expected probability among those people with direct victimisation experience is 0.27 . For indirect victimisation experience, the relevant fitted probabilities are 0.68 (no experience) and 0.38 (experience).

Focusing on the most extreme worry about crime category (i.e. dysfunctional, more than once a week), the fitted probability for someone without direct victimisation experience is 0.04 , but for someone with direct victimisation it is 0.17 . Similarly, the fitted probability for someone without indirect victimisation experience is 0.02 , but for someone with direct victimisation it is 0.15 .

Table 5. Predicted probability of worry about crime group membership, given direct victimisation experience

\begin{tabular}{|l|c|c|}
\hline Categories of worry about crime & Fitted probabilities & $\begin{array}{c}\text { Direct victimisation } \\
\text { experience }\end{array}$ \\
\hline Unworried & $\begin{array}{c}\text { No direct victimisation } \\
\text { experience }\end{array}$ & 0.27 \\
\hline Functional worry & 0.63 & 0.09 \\
\hline Dysfunctional worry - worried once a month or less & 0.06 & 0.32 \\
\hline $\begin{array}{l}\text { Dysfunctional worry - worried between once a week and } \\
\text { just less than once a month }\end{array}$ & 0.21 & 0.15 \\
\hline Dysfunctional worry - worried more than once a week. & 0.06 & 0.17 \\
\hline Total & 0.04 & 1.00 \\
\hline
\end{tabular}


Table 6. Predicted probability of worry about crime group membership, given indirect victimisation experience

\begin{tabular}{|l|c|c|}
\hline Categories of worry about crime & Fitted probabilities & \\
\hline Unworried & $\begin{array}{c}\text { No indirect victimisation } \\
\text { experience }\end{array}$ & $\begin{array}{c}\text { Indirect victimisation } \\
\text { experience }\end{array}$ \\
\hline Functional worry & 0.68 & 0.38 \\
\hline Dysfunctional worry - worried once a month or less & 0.05 & 0.07 \\
\hline $\begin{array}{l}\text { Dysfunctional worry - worried between once a week and } \\
\text { just less than once a month }\end{array}$ & 0.19 & 0.29 \\
\hline Dysfunctional worry - worried more than once a week & 0.06 & 0.10 \\
\hline Total & 0.02 & 0.15 \\
\hline
\end{tabular}

\section{Summary}

Overall, the findings contribute to the fear of crime literature by building on work by Gray and colleagues (Gray et al., 2008a; Jackson \& Gray, 2010; Gray et al., 2011; see also Chataway, Hart, \& Bond, 2019; Chataway \& Hart, 2016). First, we found that only a small number of research participants (12\%) reported frequent (defined here as 'more than once a week') dysfunctional worry about crime. This is similar to Gray et al.'s (2011) London-based study, which found that $16 \%$ respondents fell into the dysfunctional worry category. National comparisons can also be made. Drawing on data from national probability samples in Italy, Bulgaria and Lithuania, Jackson \& Kuha (2016) found that $4 \%, 6 \%$ and $10 \%$ respectively were in the 'persistent and chronic worry' group (these individuals reported being worried 'some of the time' or 'most or all of the time'). Analysing data from Round 5 of the European Social Survey, Jackson \& Kuha (2014) found that 5\% of individuals in the combined 23 European countries fell into the 'persistent' worry category, albeit that this was a pooled estimate that masked some variation (e.g. it was $10 \%$ in Portugal, $4 \%$ in the UK and $1 \%$ in Denmark).

Second, like Gray et al. (2011) we found that direct and indirect victimization experience was associated with more frequent and dysfunctional worry about crime. This is not terribly surprising, but it is important to produce evidence that suggests worry has the potential to 'flip' from infrequent/functional into frequent/dysfunctional when people experience victimization personally and/or vicariously. Third, the more disorder people saw in their neighbourhoods, the more likely they were to fall into the top two fear of crime categories ('dysfunctional worry - worried between once a week and just less than once a month and 'dysfunctional worry - worried more than once a week'). This departs a little from Gray et al.'s (2011) work, who found that perceived disorder differentiated between the 'unworried' and each of the other four different types of fear. Finally, perceived collective efficacy was also a significant predictor in the current study, albeit less strongly related to worry about crime compared to disorder. In Gray et al. (2011), collective efficacy played a very similar role to disorder.

\section{Limitations}

Some limitations of the study must be acknowledged. This was a cross-sectional survey, so we have insight into dynamics over time and we cannot engage in causal inference. Nor did we use experience sampling methods (see Solymosi, Bowers, \& Fujiyama, 2015, 2018; Chataway \& Hart, 2016; Chataway, Hart, \& Bond 2019). Ideally, we would have taken into account social and structural characteristics of the neighbourhood (see Brunton-Smith et al., 2014; Côté-Lussier et al., 2015) and use innovative statistical techniques to estimate cluster-level means and variance (Brunton-Smith, 
Sturgis, \& Leckie 2018; Jackson et al., 2019). But the sample design precluded that.

\section{A comprehensive and tailored response to fear of crime}

From a policy perspective, the results of this study reinforce the findings of Gray et al. (2011) regarding functional fear. They demonstrate that given the right socio-spatial context some residents have the capacity to manage their worry without negative impacts in a way that also reduces that worry.

These findings demonstrate the importance of taking a comprehensive and tailored approach to addressing functional and dysfunctional fear of crime at the neighbourhood level through targeted community programs that emphasise social inclusion and increase resident participation, reduce signs of disorder, encourage pro-social precautions, 'activate' streetscapes in consultation with local communities and draw on the support of ongoing interagency collaboration.

Effective removal of signs of community disorder, upkeep in public areas and ensured accessibility are almost always likely to be broadly effective. Reducing visible signs of disorder can reduce the anxiety of some residents about the capacity for crime in an area, however, there is no single approach to such strategies and each locality is likely to respond differently to a variety of initiatives. While 'activating' street spaces and encouraging street art in one area might be seen to reduce community disorder to residents, in another it may appear to some to facilitate it. Community involvement is key to implementing the best local strategies. Such programs should be approached with a clear set of goals and an evaluation strategy to establish whether they do indeed reduce worry about crime, in conjunction with the measurement of related goals.

While some precautionary measures are unlikely to reduce worry, others clearly can. Encouraging pro-social responses to worry about crime that do not negatively affect citizens' quality of life could include campaigns about how to get involved in neighbourhood groups, community associations and non-worry inducing information about how to stay secure at home and in public. However, the targeting of these resources is also important given the small percentage of residents that worry intensely.

Streetscape activation and applying the principles of Crime Prevention Through Environmental Design (CPTED) speak directly to the findings. The spaces that appear frightening or worrying to respondents tend to be of two types and both intensify worry in evening periods. The first are spaces that tend to be empty of people, relatively poorly lit, and exhibit signs of disrepair and disorder. The second are activated spaces where singular drinking cultures are dominant and where the perceptions of drunken or drug-affected behaviours disincentivise diverse use of public space. Improved street-lighting, clear way-finding, and other CPTED style interventions may reduce worry about some areas of the city. In some cases spatial activation can render underused spaces userfriendly.

There are many potential solutions to worry about crime that require a concerted, interagency approach, as many of these solutions straddle local, state and federal jurisdictions. These include improvement to public transport amenity, upkeep and regulation of public and social housing, allocation of policing resources, regulation of alcohol and illicit substances and public health responses to fear of crime. Interagency collaboration is essential to managing these layers of governance to ensure that public spaces are ordered in ways that reflect their diverse audiences, each with their own expectation of the right to peaceful enjoyment.

\section{Conclusion}

This research shows that the majority of the City of Sydney participants surveyed here do not experience episodes of worry about crime, and of those that do, most do not experience worry 
regularly or intensely. However, around $13 \%$ of respondents report being worried about one or more categories of crime on a weekly basis or more. While a percentage of these respondents will, based on previous research (Ditton et al., 2000), likely be anxious individuals, many are likely to have experienced victimisation first hand or have had someone close to them experience victimisation, or live in situations that lead them to feel their situation is somewhat precarious - perceiving their area as lacking informal social control, capacity for collective efficacy, or perceiving the area to be disorganised. While only a small percentage of respondents exhibited functional fear, this does reinforce the point that some people are able to convert their worry into positive behaviours with positive outcomes - particularly if they perceive their community and environment as supportive. This has implications for policy and interventions that focus on community building, social cohesion, and the minimisation of perceived individual and social vulnerabilities. 


\section{References}

Bernard, Y. ( 1992). North American and European Research on Fear of Crime. Applied Psychology: An International Review, 41, 65-75.

Brunton-Smith, I., Jackson, J., \& Sutherland, A. (2014). Bridging structure and perception: On the neighbourhood ecology of beliefs and worries about violent crime. British Journal of Criminology, 54(4), 503-526.

Brunton-Smith, I., Sturgis, P., \& Leckie, G. (2018). How collective is collective efficacy? The importance of consensus in judgments about community cohesion and willingness to intervene. Criminology, 56(3), 608-637.

Chataway, M. L., \& Hart, T. C. (2016). (Re) Assessing contemporary "fear of crime" measures within an Australian context. Journal of Environmental Psychology, 47, 195-203.

Chataway, M. L., Hart, T. C., \& Bond, C. (2019). The social-psychological process of fearing crime: Developing and testing a new momentary model of victimisation worry. Australian \& New Zealand Journal of Criminology, 52(4), 462-482.

Côté-Lussier, C., Jackson, J., Kestens, Y., Henderson, M., \& Barnett, T. A. (2015). A child's view: social and physical environmental features differentially predict parent and child perceived neighborhood safety. Journal of urban health, 92(1), 10-23.

Ditton, J., \& Farrall, S. (2000). The Fear of Crime. London: Ashgate.

Ditton, J., Farrall, S., Bannister, J., \& Gilchrist, E. (2000). Crime surveys and the measurement problem: Fear of crime. Doing criminological research, 142-156.

DuBow, F., McCabe, E., \& Kaplan, G. (1979). Reactions to crime : a critical review of the literature. Washington DC: National Institute of Law Enforcement and Criminal Justice Retrieved from http://babel.hathitrust.org/cgi/pt?id=pur1.32754077577900;q1=dubow\%201979;page=root;seq=9;view =plaintext; size $=100 ;$ orient $=0$

European Social Survey (2011). 'Trust in justice: Topline findings from the European Social Survey', ESS Topline Results Series Issue 1. By Jackson, J., Hough, M., Bradford, B., Pooler, T. M., Hohl, K. and Kuha, J. Available at: http://www.europeansocialsurvey.org/docs/findings/ESS5 toplines issue 1 trust in justice.pdf.

Farrall, S. (2004). Revisiting crime surveys: Emotional responses without emotions? OR Look back in anger. International Journal of Social Research Methodology, 7(2), 157-171.

Farrall, S., Bannister, J., Ditton, J., \& Gilchrist, E. (1997). Questioning the measurement of the fear of crime: Findings from a major methodological study. British Journal of Criminology 37(4), 31.

Farrall, S., \& Gadd, D. (2004). Research Note: The Frequency of the Fear of Crime. British Journal of Criminology, 44(1), 5.

Farrall, S., Jackson, J., \& Gray, E. (2009). Social Order and the Fear of Crime in Contemporary Times. Oxoford: Oxford University Press.

Farrell, G., Tilley, N., \& Tseloni, A. (2014). Why the crime drop? Crime and justice, 43(1), 421-490.

Ferraro, K., \& LaGrange, R. (1987). The measurement of fear of crime. Sociological Inquiry, 57(1), 31.

Garofalo, J., \& Laub, J. (1978). The Fear of Crime: Broadening our Perspective. Victimology, 3, $242-253$.

Gerber, M., Hirtenlehner, H., \& Jackson, J. (2010). Insecurities about crime in Germany, Austria and Switzerland: A review of research findings. European Journal of Criminology, 7(2), 141-157.

Gray, E., Jackson, J., \& Farrall, S. (2008a). Reassessing the Fear of Crime. European Journal of Criminology, $5(3), 17$.

Gray, E., Jackson, J., \& Farrall, S. (2008b). Researching everyday emotions: towards a multi-disciplinary investigation of the fear of crime. In H. Kury (Ed.), Fear of crime - punitivity: new developments in theory and research (Vol. 3, pp. 3-24). Bochum, Germany: Universitätsverlag Brockmeyer.

Gray, E., Jackson, J., \& Farrall, S. (2011). Feelings and Functions in the Fear of Crime: Applying a New Approach to Victimisation Insecurity. British Journal of Criminology, 51(1), 75-94.

Hale, C. (1996). Fear of Crime: A Review of the Literature. International Review of Victimology, 4(2), 79-150.

Hollway, W., \& Jefferson, T. (2000). Doing Qualitative Research Differently: Free Association, Narrative and the Interview Method. London: SAGE.

Hough, M. (2004). Worry about crime: mental events or mental states? International Journal of Social Research Methodology, 7(2), 171-176.

Jackson, J., Brunton-Smith, I., Bradford, B., Oliveira, T. R., Posch, K., \& Sturgis, P. (2019, December 4). Police Legitimacy and the Norm to Cooperate: Using a Mixed Effects Location-Scale Model to Estimate the Strength of Social Norms at a Small Spatial Scale. https://doi.org/10.31235/osf.io/jb74u

Jackson, J., \& Gray, E. (2010). Functional Fear and Public Insecurities About Crime. British Journal of Criminology, 50(1), 1-22. 
Jackson, J., \& Kuha, J. (2014). Worry about crime in a cross-national context: a model-supported method of measurement using the European Social Survey. Survey Research Methods, 8(2), 109-125.

Jackson, J., \& Kuha, J. (2016). How theory guides measurement: Public attitudes toward crime and policing. Handbook on Measurement Issues in Criminology and Criminal Justice, 377-415.

Jackson, J., \& Stafford, M. (2009). Public health and fear of crime: A prospective cohort study. British Journal of Criminology, 49(6), 832-847.

Lee, M. (1999). The fear of crime and self-governance: towards a Genealogy. Australian \& New Zealand Journal of Criminology, 32(3), 227-246.

Lee, M. (2001). The genesis of 'fear of crime'. Theoretical Criminology, 5, 467-485.

Lee, M. (2007). Inventing Fear of Crime: Criminology and the politics of anxiety. Devon: Willan.

Lee, M. (2015). Fear, Vulnerability and Victimisation. In P. Davies, P. Francis, \& C. Greer (Eds.), Victims, Crime and Society: An introduction (2nd ed., pp. 400). London: SAGE.

Lee, M., \& Ellis, J. R. (2018). Qualifying Fear of Crime: Multi-Methods approaches. In M. Lee \& G. Mythen (Eds.), Routledge International Handbook of Fear of Crime (pp. 155-169). Oxon: Routledge.

Lee, M., \& Farrall, S. (2009). Fear of crime: critical voices in an age of anxiety. Oxon: Routledge.

Lee, M., \& Mythen, G. (2018). The Routledge International Handbook on Fear of Crime: Routledge.

Loader, I., Girling, E., \& Sparks, R. (2000). Crime and social change in middle England. In: Routledge, London.

Russo, S., \& Roccato, M. (2010). How long does victimization foster fear of crime? A longitudinal study. Journal of Community Psychology, 38(8), 960-974.

Sakip, S. R. M., Joharia, N., \& Sallehb, M. N. M. (2012). The Relationship between Crime Prevention through Environmental Design and Fear of Crime. Procedia - Social and Behavioral Sciences, 68, 628-636.

Sampson, R. J., \& Groves, W. B. (1989). Community structure and crime: Testing social-disorganization theory. American journal of sociology, 94(4), 774-802.

Sargeant, E. (2017). Policing and collective efficacy: the relative importance of police effectiveness, procedural justice and the obligation to obey police. Policing and Society, 27(8), 927-940. doi:10.1080/10439463.2015.1122008

Simon, J. (2018). After the culture of fear: Fear of crime in the United States half a century on. In The Routledge International Handbook on Fear of Crime (pp. 82-92). Oxon: Routledge.

Skogan, W. (1981). Issues in the measurement of victimisation US Department of Justice. Washington, DC: US Government Printing Office

Solymosi, R., Bowers, K., \& Fujiyama, T. (2015). Mapping fear of crime as a context-dependent everyday experience that varies in space and time. Legal and Criminological Psychology, 20(2), 193-211.

Solymosi, R., Bowers, K. J., \& Fujiyama, T. (2018). Crowdsourcing subjective perceptions of neighbourhood disorder: Interpreting bias in open data. The British Journal of Criminology, 58(4), 944-967.

Stafford, M., Chandola, T., \& Marmot, M. (2007). Association between Fear of Crime and Mental Health and Physical Functioning. American Journal of Public Health, 97, 2076-2081.

Vold, G., Bernard, T., \& Snipes, J. (2002). Theoretical Criminology (5th ed.). New York: Oxford University Press.

UK Government (2015) 2010 to 2015 government policy: crime prevention, https:/www.gov.uk/government/publications/2010-to-2015-government-policy-crimeprevention/2010-to-2015-government-policy-crime-prevention\#appendix-4-community-safetypartnerships accessed 10/05/2019.

Warr, M. (2000). Fear of crime in the United States: Avenues for research and policy. Criminal Justice, 4, 39.

Wickes, R., Zahnow, R., Corcoran, J., \& Hipp, J. R. (2019). Neighbourhood social conduits and resident social cohesion. Urban Studies, 56(1), 226-248. 